\title{
FABIEN DUBOSSON, Dés-admirer Barrès. Le prince de la jeunesse et ses contre-lecteurs (1890-1950)
}

\section{Michela Gardini}

\section{OpenEdition}

\section{Journals}

\section{Edizione digitale}

URL: https://journals.openedition.org/studifrancesi/44178

DOI: 10.4000/studifrancesi.44178

ISSN: 2427-5856

\section{Editore}

Rosenberg \& Sellier

\section{Edizione cartacea}

Data di pubblicazione: 1 juin 2021

Paginazione: $240-241$

ISSN: 0039-2944

\section{Notizia bibliografica digitale}

Michela Gardini, «FABIEN DUBosson, Dés-admirer Barrès. Le prince de la jeunesse et ses contre-lecteurs (1890-1950)», Studi Francesi [Online], 193 (LXV | I) | 2021, online dal 01 juillet 2021, consultato il 15 octobre 2022. URL: http://journals.openedition.org/studifrancesi/44178 ; DOI: https://doi.org/10.4000/ studifrancesi. 44178

Questo documento è stato generato automaticamente il 15 octobre 2022

\section{(c) (i) (9)}

Creative Commons - Attribuzione - Non commerciale - Non opere derivate 4.0 Internazionale - CC BYNC-ND 4.0

https://creativecommons.org/licenses/by-nc-nd/4.0/ 


\title{
FABIEN DUBOSSON, Dés-admirer Barrès. Le prince de la jeunesse et ses contre- lecteurs (1890-1950)
}

\author{
Michela Gardini
}

\section{NOTIZIA}

FABIEN DUBosson, Dés-admirer Barrès. Le prince de la jeunesse et ses contre-lecteurs (1890-1950), Paris, Classiques Garnier, 2019, 770 pp.

1 L'obiettivo del volume - diviso in due parti: «L'invention du barrésisme» (pp. 39-236); «Se déprendre d'un maître: de quelques admirateurs devenus "contre-lecteurs"» (pp. 239-751) - non è quello di dimostrare la modernità di Barrès, bensì quello di documentare e spiegare come il "barresismo" sia stato un fenomeno importante tra la fine dell'Ottocento e l'inizio del Novecento almeno fino agli anni Venti: «Nous ne croyons pas qu'il y ait encore une modernité de Barrès; - scrive l'A. - en revanche, il est tout à fait intéressant de se demander en quoi il a pu être moderne pour d'autres, à une époque pas si lointaine de la nôtre» (p. 14). È inconfutabile, infatti, che Maurice Barrès abbia esercitato una grandissima influenza su numerosi scrittori suoi contemporanei, $\mathrm{i}$ quali hanno trovato nell'autore dei Déracinés una "postura", un modello autoriale estremamente produttivo che oggi, diventato ormai obsoleto, può risultare incomprensibile.

2 Lo studio si focalizza, quindi, sulla ricezione di Barrès da parte dei suoi contemporanei, in gran parte giovani lettori con aspirazioni letterarie ai quali Barrès non ha mai lesinato il proprio incoraggiamento. L'A. individua tre contesti in cui la ricezione di Barrès si è rivelata molto prolifica. In primo luogo gli scrittori simbolisti degli anni 1890 che gravitavano intorno alla Revue Blanche, come Camille Mauclair e Léon Blum; poi gli intellettuali riuniti intorno alla NRF a cominciare da André Gide, per continuare con Albert Thibaudet e Jacques Rivière; infine i surrealisti da Louis Aragon sino a Joseph 
Delteil, anch'egli membro del movimento surrealista prima di esserne escluso da André Breton.

3 L'analisi dell'A. da un lato mette l'accento sul fatto che l'ammirazione tributata a Barrès aveva per protagonisti delle personalità molto eterogenee tra loro; dall'altro lato intende far luce anche sul fatto che l'impegno politico oltre che letterario di Barrès non di rado ha provocato delle vere e proprie lacerazioni tra i suoi ammiratori, come nel caso di Léon Blum all'indomani dell'Affaire Dreyfus. In questo senso i suoi ammiratori si sono talvolta trasformati in contre-lecteurs, come recita il titolo. Nella Conclusione (pp. 753-764) l'A. ripercorre le fasi e le ragioni del declino del "barresismo" nel corso del Novecento, in un'epoca all'insegna di un radicale rinnovamento dei canoni estetici: «Avec l'œuvre théorique et littéraire de Blanchot, avec le Nouveau Roman puis Tel Quel, l'avant-garde annonce, sous différentes formes, la disparition de l'auteur» (p. 762). 